\title{
Removal of oxidable contaminations contained in submarine atmosphere
}

Ryszard Kłos, Assoc. Prof.

Polish Naval Academy

\section{ABSTRACT}

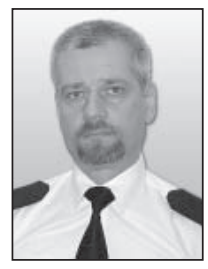

To remove flammable contaminations from submarine atmosphere, devices for their oxidation and chemical absorption of products resulting from the chemical reaction ${ }^{1}$, can be applied. In this paper a catalytic system designed for hydrogen and carbon monoxide oxidation and its tests are presented.

Keywords: breathing atmosphere contaminations, submarine, catalytic reaction

\section{KINDS AND SOURCES OF SUBMARINE ATMOSPHERE CONTAMINATIONS}

Contamination of breathing medium due to components which generate toxic action to the human body is always undesirable. The contaminations of the air in an ecologically closed atmosphere can be split into three groups: those coming from the air itself, those coming from technical means being in contact with breathing medium ${ }^{2}$, and those emmitted by the human body.

Typical air contaminations are the following: carbon dioxide, hydrocarbons, carbon oxide etc. The contaminations emmitted by the human body are similar as to their kind but of a much greater amount as a rule. For the designing purposes of life preservation systems in habitats, mean values of contaminations emmitted by the human body are determined [1]. The ship classification societies provide typical kinds of contaminations coming from technical means and their maximum permissible concentrations [1]. The data concerning safe concentration values of the contaminations in submarine breathing atmosphere can be found also in military manuals and standards, e.g. [2]. On board submarine, apart from those hazardous for human health, also other contaminations which create fire fazard such as hydrogen released as a result of electric battery gassing, can be found.

\section{HYDROGEN OXIDATION PROCESS}

A prototype device for hydrogen catalytic burning was comprised of a metal reactor filled with a catalyst. For the tests was applied the catalyst in the form of $0.5 \%$ platinum placed on alumina bars of $3 \mathrm{~mm}$ diameter, made by Johnson Matthey Ltd. When operating, the reactor with all its content was heated from outside with the use of a heating tape and simultaneously cooled $^{3}$ from inside with water, through a membrane, Fig. 1a and $b$. The reactor's prototype was fitted with a set of measuring instruments intended for the monitoring of pressure, flow rate and temperature, as well as an analyzer for the measuring of hydrogen content in after-reaction mixture ${ }^{4}$. In Fig. 2 an overall view of the reactor placed on the test stand is presented.
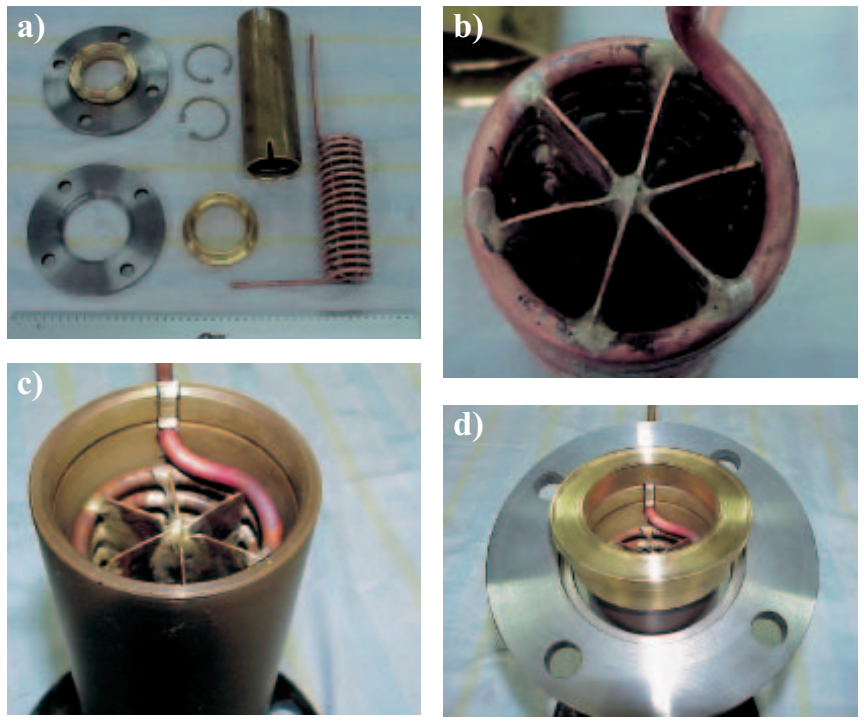

Fig. 1. Elements of the hydrogen combusting device: a) elements of the reactor; b) ribbing of the cooler; c) way of assembling the attachment; d) the ready-to- use attachement

${ }^{1}$ combustion products are usually water vapour and carbon dioxide

${ }^{2}$ e.g. volatile components of paints, thermal insulation materials, maintenance means, etc.

${ }^{3}$ if necessary

${ }^{4}$ after leaving the reactor 

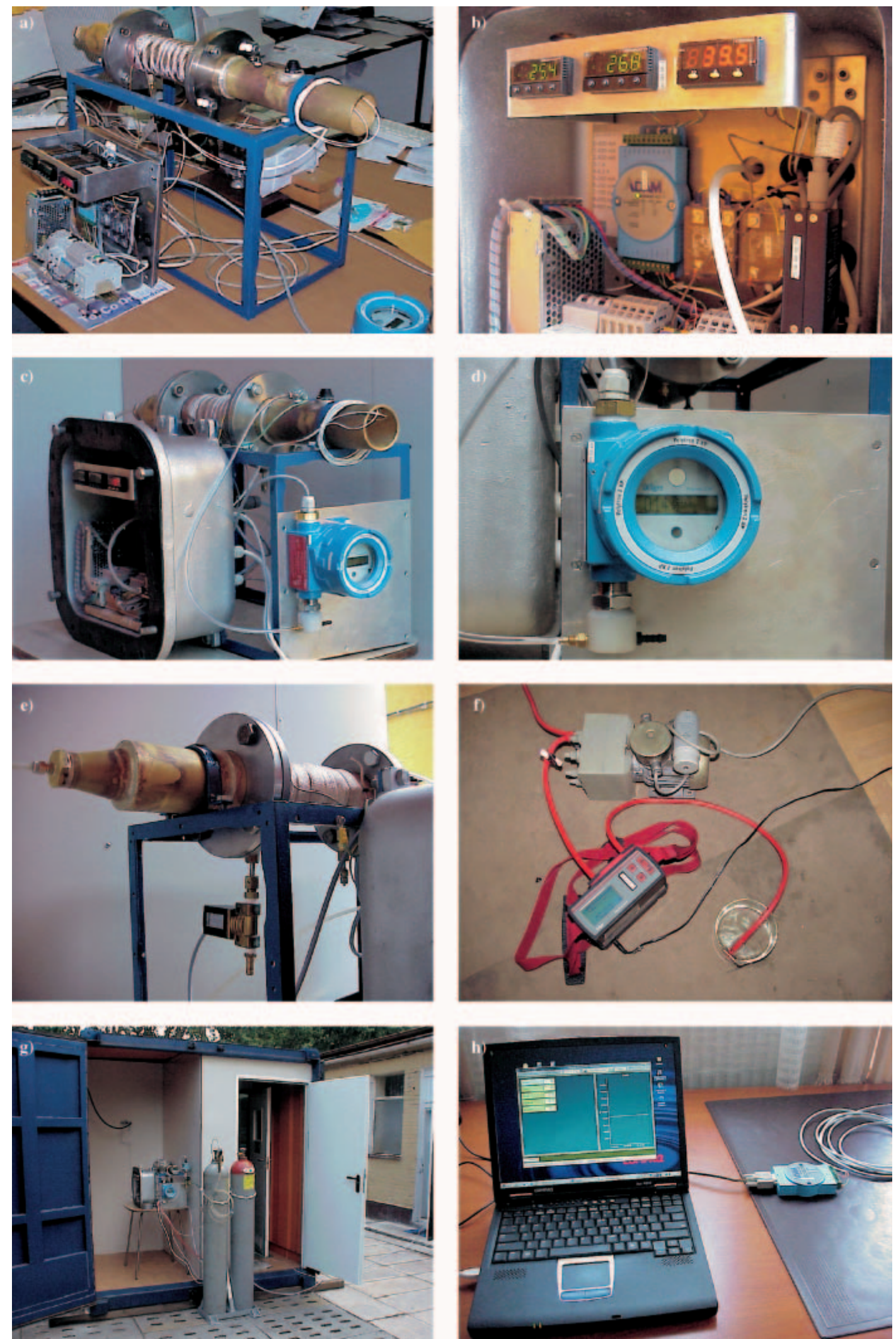

Fig. 2. The test stand and reactor's instrumentation: a) reactor and control panel; b) control panel; c) testing system; d) POLYTRON $2 X P$ analyzer; $\boldsymbol{e})$ inlet of gas for reaction; $\boldsymbol{f}$ ) suction pump and MULTIWARN multi-channel analyzer; $\boldsymbol{g}$ ) test stand; $\boldsymbol{h}$ ) recording system for test results

\section{THE TESTS}

To the hydrogen content measuring the Polytron 2XP analyzer of the Dräger firm ${ }^{5}$ was used, Fig. 2d. Its gauge was connected with the input terminal of the ADAM4517 A/C converter of the ADVANTECH firm, Fig. 2b, then through the RS485/RS232 converter - with the computer, Fig. $2 \mathrm{~h}$. This way the recording of measurement results with the use of a special software was made possible.

The measuring and control of heating tape temperature was preformed by means of the 3253 NEWPORT module, Fig. 2b. Temperature inside the reactor was also measured by means of two additional 3253 NEWPORT modules ${ }^{6}$. To the tests was applied $2 \%$ hydrogen mixture in synthetic air, whose 
flow was maintained at the rate of about $40 \mathrm{dm}^{3} \cdot \mathrm{min}^{-1}$. Before starting the tests the reactor was heated up to about $100^{\circ} \mathrm{C}$. The rise of temperature inside the reactor above $150^{\circ} \mathrm{C}$ triggered the tap water membrane cooling to start. The mixture - after passing through the reactor ${ }^{7}$ - was directed to the Polytron 2XP hydrogen content analyzer, Fig. 2d. Hydrogen content values were read in $30 \mathrm{~s}$ intervals, and the total duration time of the experiment did not excced $2 \mathrm{~h}$. The reactor test results for different temperature values kept on the heating jacket are presented in Fig. 3. The hydrogen content never exceeded the value of $0.2 \%_{\mathrm{v}}$, that complied with the requirements for the submarine of KILO class.

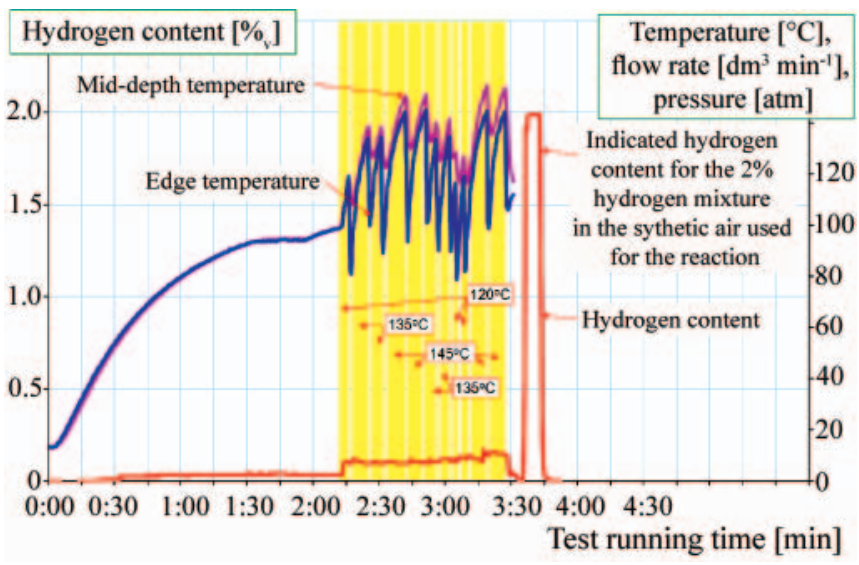

Fig. 3. Results of the hydrogen content measurements at the outlet from the reactor

\section{THE CO OXIDATION REACTOR}

The prototype of the device for $\mathrm{CO}$ catylitic oxidation is the same as that before described, however in this case its working temperature is different. Its tests were carried out in the same way as before with the exception of the reaction gas which was now $1.8 \% \mathrm{CO}$ mixture in the synthetic air. The tests showed that in this case a much higher temperature is necessary to carry out the reaction with a suitable effectiveness. For the measuring of $\mathrm{CO}$ content in the after-reaction mixture one of the channels of the MULTIWARN analyzer ${ }^{8}$, was used, Fig. 2f. From the test results shown in Fig. 4 it can be stated that the $\mathrm{CO}$ after-burning process down to the $\mathrm{CO}$ content of $0.02 \%$ is possible.

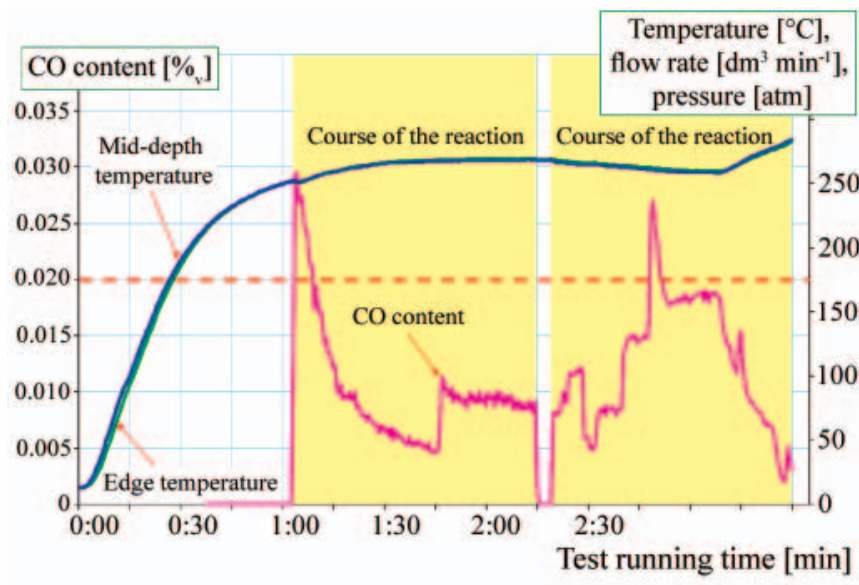

Fig. 4. Results of the measurements of temperature and $\mathrm{CO}$ content at the inlet from the reactor
Good correlation between the CO content in the afterreaction mixture and the reaction temperature was observed. On this basis it was concluded that the temperature should be maintained on the level of about $300^{\circ} \mathrm{C}$, Fig. 5 .

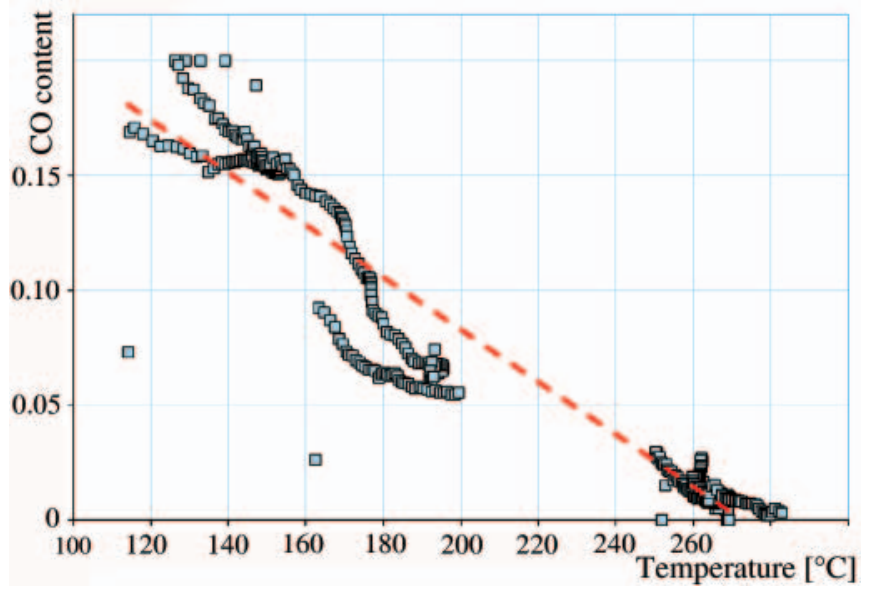

Fig. 5. The relation between carbon oxide concentration in after-reaction mixture and reaction temperature

And, the effectiveness tests of oxidation process of hydrocarbon vapours was also performed. From the tests it results that working conditions of such reactor should be similar to those for carbon oxide oxidation.

\section{CONCLUSIONS}

The elaborated prototype device meets the requirements put for the similar hydrogen after-burning device installed on board the submarine of KILO class. However the novel device is 50 times smaller than that compared and is additionally capable of burning carbon oxide and hydrogen vapours.

\section{Additional note}

This project has been finacially supported by The Polish Ministry of National Defence (MON), (Contract No. 20/DPZ/3/ OTM/S/WR/MON/2002/706)

\section{BIBLIOGRAPHY}

1. Kłos R.: Diving devices fitted with breathing mixture regeneration (in Polish), Publ. by KOOPgraf, Poznań 2000

2. Руководство по борьбе за живу есть подводной лодки РБЖ-ПЛ-82 (in Russian): Военное Издательство (Military Publishing House), Moscow 1983

3. STANAG 1301: Minimum conditions for survival in a distressed submarine prior to escape or rescue. NATO Standardization Agency, Brussels 2003

\author{
CONTACT WITH THE AUTHOR \\ Ryszard Kłos, Assoc. Prof. \\ Department of Diving Technology \\ and Underwater Activities \\ Polish Naval Academy \\ Śmidowicza 69 \\ 81-103 Gdynia POLAND \\ e-mail: skrzyn@wp.pl
}

\footnotetext{
of the measurement range: $0 \div 4 \% \mathrm{H}_{2}$, and the declared maximum relative measurement error: $\pm 5 \%$

${ }^{6}$ and the module for measuring the reactor's inside temperature controlled also the electromagnetic valve of water cooling system

${ }^{7}$ in which the hydrogen after-burning process was performed

${ }^{8}$ of the measurement range of $0 \div 200 \mathrm{ppm} \mathrm{CO}$, and the declared maximum relative measurement error of $\pm 1 \%$
} 